\title{
A "VOZ" DO ALUNO NO ENSINO SUPERIOR: O SUJEITO DISCURSIVO E A (IN)CONSISTÊNCIA ARGUMENTATIVA EM PRODUÇÕES TEXTUAIS
}

\author{
Michelle Mariana Germani, Ana Luzia Videira Parisotto \\ Universidade Estadual Paulista - UNESP, Presidente Prudente, SP. Departamento de Educação, Doutorado em \\ Educação. E-mail: michelle mariana@hotmail.com
}

\begin{abstract}
RESUMO
Os atuais modelos de ensino da Língua Portuguesa fazem com que os estudantes vejam a língua como mero componente curricular, levando à dicotomização aluno/sujeito. Quando prevalece o aluno, notamos a ausência de consistência argumentativa nos textos dissertativos, que está correlacionada ao sujeito discursivo, por meio do pensamento reflexivo. Assim, são nossos questionamentos norteadores: os textos produzidos pelos alunos de último ano do curso de Direito possuem consistência argumentativa? Qual a relação do sujeito discursivo com a facilidade ou a dificuldade em argumentar? Apresentamos então um recorte de uma pesquisa maior, de base qualitativa, realizada com alunos do quinto ano do curso de Direito. Nosso objetivo foi analisar, à luz da análise de conteúdo, a consistência argumentativa e, consequentemente, o sujeito discursivo nas produções textuais investigadas. Os resultados apontam que os pesquisados claramente tomam a escrita como uma atividade burocrática, com ausência de consistência argumentativa, sem transparecer o sujeito discursivo.
\end{abstract}

Palavras-chave: Escrita, ensino superior, produção textual, sujeito discursivo, consistência argumentativa.

\section{THE "VOICE" OF THE STUDENT IN HIGHER EDUCATION: THE DISCURSIVE SUBJECT AND THE ARGUMENTATIVE (IN)CONSISTENCY IN TEXTUAL PRODUCTIONS}

\begin{abstract}
The current Portuguese language teaching models make the students see the language as a mere curricular component, leading to the student/subject dichotomization. When the student prevails, we notice the lack of argumentative consistency in the dissertative texts, which is correlated to the discursive subject, through reflective thinking. So, are our guiding questions: do the texts produced by the last year students of the law course have argumentative consistency? What is the relationship of the discursive subject with the ease or difficulty of arguing? We present a cut of a larger qualitative research carried out with students of the fifth year of the Law course. Our objective was to analyze, in the light of the content analysis, the argumentative consistency and, consequently, the discursive subject in the textual productions investigated. The results point out that the respondents clearly take writing as a bureaucratic activity, with an absence of argumentative consistency, without disclosing the discursive subject.

Keywords: Writing, higher education, textual production, discursive subject, argumentative consistency.
\end{abstract}




\section{INTRODUÇÃO}

Por muito tempo, o ensino da Língua Portuguesa esteve umbilicalmente atrelado ao ensino de gramática. Esse modelo nos remete a conceitos de língua e de linguagem estáticos, descontextualizados e dissociados do uso efetivo da língua nas interações verbais, no qual a língua é entendida como simples componente curricular.

A princípio, precisamos entender o significado das palavras aluno e sujeito. Aluno provém do latim alumnu, "primitivamente designando criança dada para criar" (SILVA, 2004, p. 40). 0 dicionário Aurélio traz como significado "pessoa que recebe instrução e/ou educação de algum mestre, ou mestres, em estabelecimento de ensino ou particularmente; estudante, educando, discípulo. Aquele que tem escassos conhecimentos de certa matéria, ciência ou arte; aprendiz" (FERREIRA, 1986, p. 95). Evidente, portanto, a noção de incompletude do ser enquanto criança, tendo a necessidade de se desenvolver, e isso se dá pela instrução.

Já a palavra sujeito é muito bem definida por Morin (2002, p. 127) como "não apenas ator, mas autor, capaz de cognição/escolha/decisão". Inequívoco que não vislumbramos essa tendência no Ensino Fundamental, Médio ou Superior, predominando uma massificação dos discursos e atividades docentes em relação aos alunos, o que tem levado à formação de alunos/indivíduos, e não de sujeitos. Logo,

Nossos alunos, ao serem tratados como números, massa, contingente, demanda, clientela, estão saindo da escola menos propensos a aprenderem do que quando entraram, no sentido de que não temos conseguido expandir seus interesses mais puros por aprender e descobrir o funcionamento do mundo em que vivem e assim a possibilidade de se tornarem sujeitos. (FIOCCO, 2013, p. 4)

O sujeito discursivo, cujo papel o aluno não consegue assumir, estabelece, por força da sua condição, uma ordem de ações (caracterizadoras de comprometimentos e atitudes específicas) contingenciais de uma relação dialética com a sua língua materna, percebida por ele, sujeito, como um instrumento de interação sociocomunicativa. Assim, a escola tem formado simples alunos e não sujeitos. Consequentemente, o aluno, em tese, tende a dominar o conteúdo relativo à disciplina escolar, ao passo que o sujeito discursivo é quem deve dominar a língua materna (o sujeito constitui a linguagem e é constituído por ela). Quando presente essa dicotomização (aluno/sujeito discursivo), encontramos sérias deficiências no desenvolvimento da competência escritora.

Entre as deficiências, verificamos a ausência de domínio da modalidade escrita padrão da Língua Portuguesa. O domínio deficiente da língua materna penaliza a constituição do sujeito discursivo em relação à escrita e suas habilidades leitoras, fator que contribui para a formação deficitária do graduando. Instaura-se, então, o pernicioso processo de dicotomização entre estudante e sujeito do discurso, com impactos diretos e negativos no letramento desses indivíduos.

Ao exigirmos de um aluno que ele argumente ou desenvolva um texto dissertativo, estamos solicitando que deixe transparecer seu sujeito discursivo, ou seja, que exponha um pensamento crítico-reflexivo. Desta forma, "o ensino que é voltado para a interação verbal, proporciona aos alunos condições e possibilidades de se constituírem como sujeitos, que organizam seus enunciados na interação com outros sujeitos nas relações cotidianas" (LUZZI, 2014, p. 632).

Do mesmo modo, Oliveira (2003, p. 123) elucida-nos, sob a perspectiva de Bakhtin, que [...] é através das vozes, concebidas como manifestações de consciências que dialogam, debatem, confrontam-se, concordam, silenciam a voz do outro ou a si próprio [...]. As vozes, personificação de diferentes sujeitos, de diferentes visões de mundo, de opinião, estabelecem entre si um tipo de relações, que Bakhtin chama de relações dialógicas, relações extralingüísticas, que, não podem ser separadas do campo do discurso [...]. 
O mecanismo de desempenho linguístico do aluno (incluímos aqui a escrita) seria satisfatório se formado no Ensino Fundamental e desenvolvido no Ensino Médio e Superior. Ou seja, defasagens quanto à argumentação no Ensino Superior possuem suas origens nos níveis de ensino precedentes.

Nesse diapasão, ressaltamos que a consistência argumentativa está interligada à capacidade de envolver o leitor por meio da lógica e de argumentos convincentes. É preciso que o escritor deixe suas marcas, pois, caso contrário, o texto escrito "[...] se limita à reprodução de um modelo, e a tarefa de leitura, ao reconhecimento do modelo reproduzido. Em conjunto, representam nada mais do que um processo de sedimentação do modelo e a consequente anulação das partes não absorvidas por ele" (PÉCORA, 2011, p. 100).

Portanto, as oportunidades de escrita em que impera o lugar-comum acabam se consolidando em processos de falsificação da escrita, isto é, as produções textuais se tornam momentos de simples reproduções de um mundo já admitido. Por isso, a consistência argumentativa está interligada ao sujeito discursivo, por meio do pensamento reflexivo, visto que a ausência deste é próprio da precariedade no domínio da modalidade escrita formal, e indubitavelmente isso irá limitar a qualificação profissional do graduando.

Nesse sentido, apresentamos, neste artigo, um recorte de uma pesquisa maior de mestrado, desenvolvida nos anos 2016 e 2017, a qual teve como intuito traçar um diagnóstico e apontar caminhos para as dificuldades de domínio da competência escritora. Nossos sujeitos foram os alunos do último ano do curso de Direito de uma Instituição de Ensino Superior (IES) Pública e uma IES Privada do interior do estado de São Paulo. Entre tantos instrumentos de coleta de dados, trabalhamos com a aplicação de produções textuais junto aos alunos.

Com o vasto material coletado, após minuciosa análise, chamou-nos a atenção a falta de consistência argumentativa nos textos produzidos pelos investigados, elemento este relacionado ao sujeito discursivo.

Diante desse quadro, surgiram-nos as seguintes questões: os textos produzidos pelos alunos de último ano do curso de Direito possuem consistência argumentativa? Qual a relação do sujeito discursivo com a facilidade ou a dificuldade em argumentar?

Dessa forma, nosso objetivo para este artigo, baseando-nos no recorte estabelecido, é analisar a consistência argumentativa e, consequentemente, o sujeito discursivo (presente ou ausente) nas produções textuais que foram instrumentos de nossas análises.

\section{METODOLOGIA}

Considerando como objeto de estudo a escrita no ensino superior, desenvolvemos uma pesquisa qualitativa, com enfoque descritivo analítico, em duas instituições de ensino superior, sendo uma pública e outra privada, ambas do interior paulista.

Elegemos como sujeitos de nossa pesquisa os alunos de quinto ano do curso de Direito, visto que nossa intenção foi analisar a proficiência na escrita dos formandos. O projeto obteve parecer favorável emitido em 19/04/2016 sob o no 1.505 .837 pelo Comitê de Ética em Pesquisa da Faculdade de Ciências e Tecnologia - FCT/Unesp de Presidente Prudente.

A amostra de sujeitos englobou todos os alunos de quinto ano de ambas as instituições, e a participação foi facultada aos interessados em colaborar na pesquisa. A coleta de dados foi concretizada no primeiro semestre de 2016 na IES Privada, e no primeiro semestre de 2017 na IES Pública.

Entre os instrumentos que utilizamos, está uma produção textual. No caso, elegemos o tema "redução da maioridade penal" e formulamos uma proposta para que os alunos produzissem um texto argumentativo, abordando um tema jurídico polêmico e que se posicionassem para além do senso comum. 
Não abordaremos todas as dimensões dos textos que adotamos como critério na pesquisa originária, quais sejam: dimensão discursiva, semântica e gramatical (COSTA VAL et al., 2009). Para o presente artigo, limitar-nos-emos à dimensão discursiva. Esta, por sua vez, abrange a adequação temática e a consistência argumentativa. Em nossas análises, abordaremos somente a consistência argumentativa.

Os dados foram analisados à luz da análise de conteúdo, com respaldo teórico de Bardin (2011) e Franco (2008).

Também, omitimos os nomes dos alunos, bem como os das instituições investigadas, mantendo o anonimato. Optamos, então, por identificá-los por uma combinação alfanumérica, na qual a letra $A$ designa os alunos da instituição privada e a letra B os alunos da instituição pública. Os números cardinais, de 01 até o número máximo de investigados em cada unidade de ensino superior, representam os alunos, de forma aleatória.

\section{RESULTADOS}

Os formandos do curso de Direito não escreveram em uma situação espontânea, nem sabiam o tema sobre qual deveriam argumentar. Foram convidados a participar da pesquisa por meio da qual deveriam produzir um texto do gênero dissertativo escolar, tendo por base três textos apresentados na proposta. Destacamos, também, que a escrita se deu em uma única ocasião, sem oportunidade de reescrita.

As condições impostas aos pesquisados claramente tomam a escrita como uma atividade burocrática e escolar. Como mero objeto de avaliação, é altamente favorável à dicotomização aluno/sujeito discursivo. Apesar disso tudo, temos como atenuante o fato de essa circunstância não se mostrar rara ao estudante, que deve demonstrar um conhecimento, uma competência teoricamente construída ao longo de sua escolaridade. Não se trata de uma situação usual de comunicação sociointerativa, mas uma tentativa de sua representação em que o aluno é convidado a assumir o papel de sujeito discursivo (e é essa capacidade que lhe foi avaliada).

Analisamos 23 produções textuais da IES Privada (uma aluna não teve condições de concluir a pesquisa), e 47 produções textuais da IES Pública (10 alunos optaram por responder ao questionário, mas não elaborar a produção textual).

Precisamos admitir que a consistência argumentativa da maioria das produções da IES Privada mostrou-se deficiente, sendo esta deficiência menor na IES Pública. Os alunos que elaboraram tais produções limitaram-se a reproduzir os textos da proposta de forma parafraseada. Verificamos, também, muitas propostas com utilização do lugar-comum, ou seja, o autor deixa de emitir sua opinião para gerar ideias que acredita cristalizadas pelo seu leitor, desaparecendo as marcas do escritor.

\section{DISCUSSÕES}

Com base nos resultados, fica fácil verificar que identificamos vários casos de falta de consistência argumentativa, conforme o exemplo a seguir:

Quadro 1. Produção textual elaborada pelo aluno A01

"Menor responsável"

A redução da maioridade penal, seria uma ótima medida para que o adolescente saiba que apesar de não possuir 18 anos, ele precisa respeitar a lei, como se fosse maior de idade, Afinal, como o próprio"texto 2" cita, se o menor, aos 16 anos, é capaz de escolher em quem votar nas eleições, ele também seria capaz de responder também perante a justiça, pelos seus atos infringentes.

Fonte: texto dissertativo-argumentativo produzido pelo aluno a partir da proposta elaborada pelas pesquisadoras (2016-2017) 
O exemplo é uma de várias produções textuais completas que se reduziram a míseras linhas, sem argumentos consistentes. Já outras produções trouxeram situações de lugar-comum, com ideias clichês, pautadas em modelos, presentes na IES Privada, conforme exemplificamos:

Hoje no Brasil vemos janelas com grade, pessoas trancadas nas casa com medo da violência e muitas vezes o infrator menor esta na rua, solto, trazendo no cidadão de bem a ideia de impunidade [...]. (A03)

Acho que devemos pega pesado sim, mudando nossas leis, pois só assim, merolhariamos o basil começa do zero. Porque quem entra na sua casa pra rouba, mata, sequestra, acaba com a sua familia, não tem piedade, com a leis mas brandas mais, rígidas se tera respeito, pois ninguem merece ser refém dessa violência, refém em sua propria, casa refém do medo. (A05)

Não generalizando mas a maioria destes jovens de 16 anos acham que já são donos do mundo, que já podem decidir sobre tudo em sua vida e por isso acabam caindo no mundo do "crime", pois acham que esse é o modo mais fácil de se conseguir o que quer. (A17)

Grande parte dessas crianças que vivem do crime hoje, são por influência da própria família. Pais que usam drogas dentro de casa, ao lado dos filhos, que levam crianças para roubar/furtar, mães e até mesmo pais que se prostituem com os filhos por perto e existem muitos casos onde pai mata mãe na frente da prole ou vice-versa. (A18)

Os formandos da IES Privada possuíam conhecimentos muito além do que expuseram, considerando o nível intelectual e cognitivo, além da escolaridade e por se tratar do curso de Direito, o qual oportuniza um aprofundamento no tema da proposta de produção textual. Valeram-se de argumentos pouco convincentes, utilizados por qualquer um que não tenha domínio jurídico do assunto.

Exemplificamos uma produção da IES Pública que também deixa em evidência o lugarcomum: 
Quadro 2. Produção textual elaborada pelo aluno B38

\section{Estancar a sangria?}

Nosso sistema carcerário já cansou de dar evidências que está em condições precárias, as revoltas no começo do ano de 2017 são apenas as provas mais recentes. Celas lotadas, falta de controle e fiscalização, corrupção, tráfico interno, são estes e outros muitos problemas enfrentados que fazem com que o sistema seja falho e ineficiênte.

No Brasil, a teoria adotada pelos presídios é o da ressocialização dos detentos através da pena em cárcere privado. Nessa teoria é fundamental que os presos tenham a estrutura mínima de acomodação, lazer, alimentação e edução. Mas é o que nossos presídios vem apresentando à anos?

A crise do sistema é grave e necessita urgentemente de atenção das autoridades competentes. A recuperação dos detêntos mantem-se em níveis baixíssimos, com indíces de reincidência elevado. $E$, com todos estes problemas, como a redução em 2 anos da maioridade penal irá resolver alguma coisa?

Colocar nossos jovens de 16 anos dentro deste falido sistema seria a mesma coisa de dar mais um incentivo para eles seguirem na vida do crime, as dificuldades enfrentadas pelos detêntos provoca que a prisão funciona como uma verdadeira escola do crime.

Por fim, a efetiva "entanca da sangria" da violência é o Estado cumprir com o seu papel de garantir educação de qualidade para as crianças e jovens, além de reduzir a desigualdade social do país.

Fonte: texto dissertativo-argumentativo produzido pelo aluno a partir da proposta elaborada pelas pesquisadoras (2016-2017)

Assim, o quadro vislumbrado denuncia que alguns alunos da IES Pública e a maioria dos alunos da IES Privada não possuem o sujeito discursivo formado, ou seja, a escrita, neste caso, se configurou para os alunos um objeto de avaliação, não como língua materna, desaparecendo por completo sua função comunicativa. Tanto isso é verdade que os parcos argumentos que utilizaram vieram dos textos de apoio.

\section{CONCLUSÃO}

Entre as produções textuais de nossa pesquisa, notamos uma forte ausência de consistência argumentativa que, por sua vez, está relacionada ao sujeito discursivo, por meio do pensamento reflexivo, já que a falta deste é típico da fragilidade no domínio da escrita formal. Ou seja, a proposta da presente pesquisa só atingiu o aluno (mera avaliação), e não o sujeito discursivo. Percebemos que essa defasagem de escrita foi mais recorrente, em sua maioria, nas produções textuais dos alunos da IES Privada.

Diante dos textos que analisamos, percebemos que o aluno apresenta dificuldade de representar o seu papel de sujeito discursivo, numa escrita resultante de uma interação sociocomunicativa. Exatamente por isso, exibe essa dificuldade, a qual se revela na produção textual. No texto proposto, esperávamos que o estudante representasse o papel que lhe cabe (de sujeito discursivo), admitindo-se a simulação de uma interação sociocomunicativa. Porém, foi possível perceber que não houve unanimidade no êxito, ficando evidente a dicotomização entre aluno/sujeito discursivo.

Em várias produções, foi o aluno que se sobrepujou ao sujeito discursivo, e sua voz foi silenciada, dando espaço a ideias de lugar-comum ou meras paráfrases da proposta. A sua língua materna se the apresenta distorcida, descontextualizada, confinada à disciplina escolar (apenas 
lembrada por ocasião das avaliações escolares ou de concursos), não se configurando como um instrumento cultural de interação sociocomunicativa.

\section{REFERÊNCIAS}

BARDIN, Laurence. Análise de conteúdo. Tradução de Luís Antero Reto e Augusto Pinheiro. São Paulo/SP: Edições 70, 2011.

COSTA VAL, Maria da Graça et al. Avaliação do texto escolar: professor-leitor/aluno-autor. Belo Horizonte/MG: Autêntica Editora/Ceale, 2009.

FERREIRA, Aurélio Buarque de Holanda. Novo Dicionário da Língua Portuguesa. 2. ed. Rio de Janeiro/RJ: Nova Fronteira, 1986.

FIOCCO, K. E. T. W. Sujeito discursivo na aula de Geografia. In: Encontro de Geógrafos da América Latina, 2013, Lima, Peru. Anales del XIV Encuentro de Geógrafos de América Latina. Perú, Lima: Unión Geográfica Internacional Perú, 2013. v. 1. Disponível em: <http://observatoriogeograficoamericalatina.org.mx/egal14/Ensenanzadelageografia/Investigacio nydesarrolloeducativo/23.pdf >. Acesso em: 26 maio 2018.

FRANCO, Maria Laura Publisi Barbosa. Análise de conteúdo. 3. ed. Brasília/DF: Liber Livro Editora, 2008.

LUZZI, Marta. O ensino de língua portuguesa e a constituição do sujeito leitor/escritor. Estudos Linguísticos. São Paulo, 43 (2), maio/ago. 2014, p. 631-650.

MORIN, Edgar. A cabeça bem feita. 7. ed. Tradução Eloá Jacobina. Rio de Janeiro/RJ: Bertrand Brasil, 2002.

OLIVEIRA, Maria Bernadete Fernandes de. Pensando a escrita como uma prática discursiva: implicações para a pesquisa em LA. Rev. Brasileira de Linguística Aplicada, v. 3, n. 1, 2003, p. 117184. https://doi.org/10.1590/S1984-63982003000100008

PÉCORA, Alcir. Problemas de redação. 6. ed. São Paulo/SP: WMF Martins Fontes, 2011 - Coleção linguagem.

SILVA, Deonísio da. De onde vêm as palavras: origens e curiosidades da língua portuguesa. 14. ed. São Paulo/SP: A Girafa Editora, 2004. 